16. Эпидемиологическая и эпизоотологическая ситуация по бешенству в Самарской области [Электронный ресурс] // Управление Роспотребнадзора по Самарской области. - http://63.rospotrebnadzor.ru/ rss all/-/asset publisher/Kq6J/ content/id/583647.

17. Бобров В.В., Варшавский А.А., Хляп Л.А. Чужеродные виды млекопитающих в экосистемах России / ред. Ю.Ю. Дгебуадзе, В.М. Неронов. М.: Товарищество научных изданий КМК, 2008. 232 с.

18. Лавров Н.П. Итоги интродукции енотовидной собаки (Nyctereutes procyonoides Grey) в отдельные области СССР // Уч. зап. МГЗПИ. Вып. 29. М.: Просвещение, 1971. С. 101-160.

19. Насимович А.А., Исаков Ю.А. Песец, лисица, енотовидная собака. М.: Наука, 1985. 159 с.

20. Тупикова Н.В., Комарова Л.В. Принципы и методы зоологического картографирования. М.: Издво МГУ, 1979. 192 с.

21. Новиков Г.А. Полевые исследования экологии наземных позвоночных животных. М.: Советская наука, 1949. $601 \mathrm{c}$.

22. Формозов А.Н. Спутник следопыта / Предисловие, подготовка текста и дополнительные приме-

чания Н.А. Формозова. Изд. 7-е, доп. М.: КомКнига, 2006. $368 \mathrm{c}$.

23. Гептнер В.Г., Наумов Н.П., Юргенсон П.Б. и др. Млекопитающие Советского Союза. Т. 2. Ч. 1. Морские коровы и хищные. М.: Наука, 1967. 1014 с.

24. Сизонов O.В. Енотовидная собака (Nyctereutes procyonoides Gray) плавневой зоны Восточного Приазовья: дис. ... канд. биол. наук. Ставрополь, 2006. 159 с.

25. Юдин В.Г. Енотовидная собака Приморья и Приамурья. М.: Наука, 1977. 161 с.

26. Фокина М.Е., Камалова Е.С., Лапузина В.В. Анализ биотических взаимосвязей енотовидной собаки в условиях интродукции // Наука, природа и общество: Материалы конференции. Миасс-Екатеринбург: УрО PAH, 2010. C. 205-207.

27. Фокина М.Е., Камалова Е.С. Анализ распространения енотовидной собаки в пойменной части национального парка «Самарская Лука» // Материалы международной научной конференции, посвящённой 80-летию со дня рождения профессора Александра Павловича Крапивного. Харьков, 2009. С. 129-132.

\title{
SOME DATA ON RACCOON DOG'S DISTRIBUTION IN THE SAMARA REGION
}

(C) 2016

E.S. Kamalova, postgraduate student of the Chair of Ecology, Botany and Nature Protection V.V. Martynova, postgraduate student of the Chair of Ecology, Botany and Nature Protection

M.E. Fokina, candidate of biological sciences, associate professor of the Chair of Zoology, Genetics and Common Ecology Samara National Research University, Samara (Russia)

Abstract. Raccoon dog is an invasive species which has successfully expanded on the new territory in the Samara region. The paper presents data on its distribution on the Samara Region areas. The studies were conducted on the floodplain, steppe, forest and riparian areas of the region, including both national park «Samarskaya Luka» and Zhiguli State Nature Biosphere Reserve areas. Collected data proves studied species' presence (such as footprints, burrows, temporary shelters) in 12 municipal districts of the region. The paper contains information on the GPS-mapping of burrows and temporary shelters which have been found in the southern part of the protected area of the national park «Samarskaya Luka» during 2002-2015. Fifteen burrows and temporary shelters, footprints, urinary points, feces have been found in this area, and the detailed burrow's descriptions were provided. Further spread of the population depends on the places suitable for temporary shelters and burrows, presence of water reservoirs areas where raccoon dogs may find food, as well as minimized influence of disturbing factor (anthropogenic press). The data obtained may be useful for employees of nature biosphere reserves, forestry and hunting organizations for invasive species' monitoring.

Keywords: raccoon dog; Nyctereutes procyonoides; distribution; territory development; Samarskaya Luka; introduced species; behavioral activity; adaptation; special protected natural areas; Samara region; floodplain areas.

УДК $005801 / .07+00502.75$

\section{К ОЦЕНКЕ БИОЭКОЛОГИЧЕСКИХ ОСОБЕННОСТЕЙ РАСТЕНИЙ ТЮЛЬПАНА БИБЕРШТЕЙНА (TULIPA ВIEВЕRSTEINIANA SCHULT. ET SCHULT. FIL.) В МОДЕЛЬНЫХ БИОТОПАХ КРАСНОСАМАРСКОГО ЛЕСНИЧЕСТВА}

(C) 2016

М.Г. Котельникова, аспирант кафедры экологии, ботаники и охраны природы Самарский национальный исследовательский университет имени академика С.П. Королёва, Самара (Россия)

\footnotetext{
Аннотащия. В статье представлены результаты мониторинга растений тюльпана Биберштейна (Tulipa biebersteiniana Schult. et Schult. fil.), относящегося к категории редких и исчезающих видов. Путем обобщения доступных источников составлена общая характеристика морфологических и биоэкологических особенностей растения. В 2012-2015 гг. было проведено исследование растений тюльпана в двух популяционных группах квартала 80 Красносамарского лесничества. Полученные данные использовали для установления морфометрических показателей тюльпана Биберштейна, оценки уровня их изменчивости и сопоставления с указанными в литературе для данного растения количественными признаками. Было установлено, что длина побегов у растений тюльпана Биберштейна варьирует в промежутке значений от 23 см до 50 см, максимальная средняя длина в 40 см представлена у растений второй популяционной группы. Распределение длины побега у особей 30

Самарский научный вестник. 2016. № 3 (16)
} 
второй популяционной группы более стабильно, изменения в зависимости от года вегетации слабо выражены. Признак длины побега характеризуется пластичностью, его значения вписываются в диапазон значений, указанный для различных частей ареала в литературе, при значительной доле «высоких» растений в обследованной популяции. Это может свидетельствовать о благоприятности условий произрастания и возможности сохранения в составе растительных сообществ при отсутствии лимитирующих антропогенных факторов.

Ключевые слова: Tulipa biebersteiniana Schult. et Schult. fil.; морфологические и биоэкологические особенности; количественные и качественные характеристики; длина побега; Красносамарское лесничество; модельный биотоп; Самарская область.

В современных условиях ускоренной деградации природных экосистем в результате антропогенного воздействия задача сохранения биологического разнообразия становится первоочередной. Наибольшую актуальность приобретают исследования, связанные с оценкой биологического разнообразия, изучением биоэкологических особенностей видов природной флоры, в том числе редких видов высших растений. Успех их сохранения в природе или вне ее (в культуре) в значительной мере зависит от качества семян, образуемых растениями, и прохождения ими всех фаз развития в онтогенезе - от проростка до взрослой генеративной особи. В районах Самарской области на долю агроэкосистем приходится от 50 до 90\%, сохранившиеся фрагменты природных экосистем подвергаются сильному антропогенному воздействию [1]. На данный момент во флоре области насчитывается 258 редких и исчезающих видов растений [2], наша статья посвящена рассмотрению биоэкологических особенностей тюльпана Биберштейна Tulipa biebersteiniana Schult. et Schult. fil. - исчезающего вида, включенного в Красную книгу Самарской области и значительное число Красных книг других регионов России и Украины.

Род Tulipa преимущественно азиатского происхождения - центром сосредоточения наиболее декоративных видов тюльпана является Средняя Азия. Оттуда они, по мнению многих авторов, распространились на территорию южной Европы и африканское побережье Средиземного моря. Не существует единого мнения в литературе о количестве всех известных в природе тюльпанов (указывается от 100 до 160 видов) [3]. Введение в культуру дикорастущих тюльпанов затруднено из-за низкого вегетативного размножения большинства «дикарей», особенно крупноцветковых. Исследования по интродукции тюльпанов проводились многими учёными, в частности, Кудрявцевой В.М. [4] на примере коллекции из 40 видов в Белоруссии. Было отмечено, что плодоношение интродуцированных тюльпанов во многом зависит от численности особей в пределах вида. Хорошей семенной продуктивностью отличаются мелкоцветковые виды, имеющие высокий коэффициент вегетативного размножения. Опыт выращивания дикорастущих тюльпанов в средней и северо-западной зонах СССР показал, что перенос их из мест естественного происхождения в другие условия не остаётся без последствий: некоторые виды не плодоносят или завязывают невсхожие семена, другие же при выращивании на повышенном агрофоне с ежегодной выкопкой луковиц приобретают способность к вегетативному размножению [5-6].

Тюльпан Биберштейна - луковичный травянистый многолетник, столонообразующий олигокарпический или поликарпический весенний эфемероид-геофит.
Описан в 1829 г. И. Шультесом (1773-1831) и Шультесом-младшим (1804-1840) по образцам из Северного Кавказа (между Моздоком и Кизляром.). Название вида дано в честь первого коллектора, видного российского ботаника Ф.К. Биберштейна - Маршалла (1768-1826), изучавшего флору Кавказа [7]. По данным С.К. Черепанова, к данному виду отнесен ряд прежде выделявшихся отдельно синонимов - Tulipa graniticola (Klok. \& Zoz) Klok., T. hypanica Klok. \& Zoz, T. ophiophylla subsp. bestashica Klok. \& Zoz, T. ophiophylla subsp. dometzica Klok. \& Zoz, T. ophiophylla subsp. graniticola Klok. \& Zoz, T. quercetorum Klok. \& Zoz, T. scythica Klok. \& Zoz [8].

Общий ареал распространения тюльпана охватывает Среднюю Европу, Балканы и Малую Азию, Украину, Кавказ и Северный Казахстан. В России встречается в чернозёмных районах европейской части (очень редко к северу от нее) и в Западной Сибири. В Средней России на север доходит до Московской области (долина р. Оки) [9-16]. В литературе сроки цветения данного вида указываются в апреле первой декаде мая, его средняя продолжительность достигает 14 дней (Центральном Черноземье) [17]. Период плодоношения в литературе отмечается в конце мая - июне, продолжительность вегетации 53-69 дней.

Тюльпан Биберштейна размножается семенами и вегетативно (дочерними луковицами на столонах). Подземная часть растения находится на достаточно большой глубине [17] и представляет собой 1 или 2 вытянуто-яйцевидные или конусовидные луковицы, размеры которых у генеративных особей, по указанию большинства источников [7; 13; 17-20] составляют $1-1,5$ см в диаметре и до 3 см длиной, по некоторым данным длина луковиц может достигать 4 см [18]. Луковицы ядовиты [11], сужаются в выраженную несколько изогнутую шейку; покровные чешуи черно-бурые или почти черные, кожистые, матовые, опушенные изнутри. Как правило, ежегодно луковицы вегетирующих растений формируют две замещающие дочерние луковицы: одну внутри оболочки старой, другую - на конце длинного подземного столона [19].

Стебель растения тонкий, прямостоячий, голый, гладкий, примерно в средней части с двумя-тремя очередными косо вверх направленными плоскими прямыми широколинейными листьями 1-2 см шириной; обычно нижний лист более широкий (Благовещенский, Курганская, Мордовия). Показатель длины генеративного побега, согласно литературным данным, указывается в пределах 15-40 см [7; 11; 14; 20], в разных частях ареала размеры растений, по всей вероятности, варьируют. Так, в республике Башкортостан данные показатель составляет 20-40 см, в Республике Мордовия - 15-20 см, Курганской области 15-30 см [18-19, 21]. 
Котельникова М.Г.

К оценке биоэкологических особенностей растений тюльпана.

03.02.00 - общая биология

Цветок одиночный (реже встречаются растения с двумя цветками), на длинной цветоножке, которая равна или немного короче верхнего листа. Околоцветник простой, колокольчатый, снаружи жёлтый, с зеленоватыми или фиолетовыми продольными полосками посередине. Листочков околоцветника 6 , они яйцевидные, с постепенно заострённой верхушкой, 2,5-3,5 см длиной и 5-9 мм шириной [11; 19-20], наружные вдвое шире внутренних. В Оренбургской области на р. Сакмара и в долине р. Губерля, в Челябинской области на р. Уй у г. Троицк и д. Осиповка, а также в заповеднике «Аркаим» найдена редкая разновидность Tulipa biebersteiniana var. tricolor (Klok et Zoz) Knjasev, Kulikov et Philippov - тюльпан Биберштейна трёхцветный с розовыми или беловатыми листочками околоцветника [19]. Тычинок 6, вдвое короче околоцветника; их нити узколинейные, слегка расширенные (до 1,5 мм шириной), с волосистым кольцом, в 2-3 раза длиннее прилистников. Желтые линейные пыльники прикреплены к тычиночным нитям основаниями $[13 ; 21-22]$. Столбик на верхушке трёхраздельный, несколько выступает над тычинками Плод - трёхгнездная продолговато-яйцевидная коробочка с верхушкой, вытягивающейся в длинный носик, вскрывающаяся тремя продольными створками до $2-2,5$ см длиной и $1-1,5$ см шириной $[7 ; 11 ; 19-20]$. Семена многочисленные, плоские.

Тюльпан Биберштейн - полиморфный вид, представленный двумя экологическими формами: луговостепной и степной, которые различаются по ширине и толщине листьев, по степени кожистости покровных чешуй луковицы $[2 ; 11 ; 22]$. Тюльпан произрастает в сухих степях, на степных склонах, в долинах рек, выдерживая незначительное затопление, среди кустарниковых зарослей, а также на полянах, опушках и под пологом светлых широколиственных лесов, встречается в осветленных дубняках, по лесным полянам и опушкам, кустарниковым склонам балок (Благовещенский), на сухих травянистых и каменистых склонах, в можжевельниковых редколесьях [17; 23]. В научной литературе прежних лет для данного вида используется название, сейчас сведенное в синонимы - тюльпан дубравный (Tulipa quercetorum Klok. et Zoz), для биологии которого А.Ф. Терехов, в частности, отмечает: «... произрастает по степям, на склонах, в редколесье, по поймам рек» [24]. Тюльпан Биберштейна предпочитает рыхлые, песчаные субстраты [25], засоленные, перегнойно-карбонатные почвы, реже - карбонатные глинистые. Растение полутеневое, хорошо реагирует на достаточное обеспечение влагой, особенно в весенний - раннелетний периоды.

В некоторых источниках отмечается плотность и характер популяций вида. В Самарской области [2] численность вида в типичных местах обитания может быть высокой, достигая более 40-70 особей на $100 \mathrm{~m}^{2}$, однако в результате антропогенных причин (трансформация лугово-степных сообществ, массовый сбор на букеты) неуклонно снижается. В республике Мордовия [18] популяция насчитывает около трехсот экземпляров, причем зацветают не более 20 процентов особей. На территории Липецкой обл. известно около 20 популяций вида [16]. Специальные исследования, проведенные в 2010-2011 гг. показали, что численность по опушкам дубрав в западной части области невелика, но, видимо, остается стабильной. Локальные популяции Пензенской области [25], особенно в центре и на севере - небольшие по площади и плотности растений. В южных районах они значительно больше и могут занимать подходящие местообитания в пределах всего фитоценоза. Умеренный выпас скота препятствует задернению почвы и способствует поддержанию численности особей на высоком уровне: 250-4000 растений на $100 \mathrm{M}^{2}$.

Лимитирующие факторы - изменение фитоценотической среды (не выносит сильного задернения и затенения), перевыпас скота, сбор на букеты и пересадка в частные коллекции, климатические флуктации (страдает в засушливые годы). Для нормальной жизнедеятельности необходимы слабая пастбищная нагрузка, условия хорошего освещения, богатые азотом почвы и постоянное увлажнение в течение вегетационного сезона [2; 14; 17-19, 21, 25-27].

Вид отнесен к категории редких и сокращающих свою численность таксонов, внесен в Красные книги Самарской (категория ІІа - таксон, сокращающийся в численности в результате разрешения местообитаний), Ульяновской (категория 1 (Е) - вид, находящийся под угрозой исчезновения), Челябинской (категория III - редкий вид), Курганской (категория II уязвимый вид), Липецкой (категория II - сокращающийся в численности, уязвимый вид), Пензенской (категория II), Воронежской и Тамбовской областей (категория III - редкий вид), Республики Башкортостан (категория III - редкий вид), Республики Мордовия (категория 1 - исчезающий вид) [2; 16-18, 20, 2426] и др. Охраняется на территории Жигулёвского заповедника, НП «Самарская Лука» и ПП «Балка Кладовая», «Каменные лога», «Урочище Грызлы», «Мулин дол» (Большечерниговский район), «Гора Зелёная» (Елховский район), «Чубовская степь», «Каменный дол» (Кинельский район), «Байрачный колок в сухой степи», «Марьевская балка», «Балка Лозовая» (Пестравский район), «Мочалеевские реликтовые нагорные дубравы», «Гора Копейка» (Похвистневский район) и др. [16;28-32].

Целью нашей работы было определение биоэкологических особенностей растений, в частности определение показателей длины побега, длины и ширины коробочки. Сбор образцов проводился в Красносамарском лесничестве в летний период 20122015 гг. на двух соседних площадях в квартале 80 (притеррасье) и в луговом сообществе поймы реки Самара, квартал 69. В данном отчете представлены данные по растениям учетных площадей квартала 80. Ниже указана краткая характеристика учётных площадей, составленная для удобства в форме анкеты.

КСЛ, притеррасье, квартал 80, учётная площадь № 1

1) Рельеф местности: выровненный участок, 54 м над уровнем моря.

2) Тип растительности на площади: галофитная тростниково-лисохвосто-раннеосоковая (тростникововидная) ассоциация.

3) Площадь, занимаемая популяцией: $30 \times 30$ м.

4) Характер размещения экземпляров: рассеянный.

5) Подстилка - степной войлок, суглинистая почва, отмечено содержание $\mathrm{Cl}^{-}$(>10мг/100 мл, десятые доли), $\mathrm{pH}=6,2$. 
КСЛ, притеррасье, квартал 80, учётная площадь № 2

1) Рельеф местности: выровненный участок, 54 м над уровнем моря.

2) Тип растительности на площади: узколистномятликовое сообщество.

3) Площадь, занимаемая популяцией: $30 \times 30$ м.

4) Характер размещения экземпляров: рассеянный.

5) Подстилка - степной войлок, суглинистая почва, $\mathrm{pH}=5,9$.

Красносамарский лес - крупный (около 30 тыс. га) лесной массив, расположенный в зоне разнотравнотипчаково-ковыльных степей обыкновенного чернозёма. На его территории произрастает 53 вида сосудистых растений, 2 вида лишайника, внесённые в Красные книги федерального и регионального уровней. 21 вид включён в список редких и уязвимых таксонов, нуждающихся в постоянном контроле и наблюдении на территории Самарской области, 14 видов раритетны для Волго-Уральского региона [33-34]. В частности, на данном лесном массиве были найдена и обозначена 1 ценопопуляция тюльпана Биберштейна [35].

Тюльпан Биберштейна представлен исключительно генеративными формами на учетных площадях. Полученные данные по показателю длины побега представлены на рис. 1. Согласно ним, длина побега в пределах всей выборки варьирует в промежутке значений от $23 \mathrm{~cm}$ до $50 \mathrm{~cm}$, на учетной площади $1-$ от 23 до 47 см (среднее значение - 36 см), учетной площади 2 - от 27 до 50 см (40 см). Сравнивая полученные результаты с литературными источниками, обозначающими максимальную высоту побега тюльпана в пределах 15-40 см, можно отметить, что в квартале 80 значения показателя значительно превышают указанные в литературе (средняя высота достигает 3640 см), наблюдается значительная доля высоких растений в изучаемых биотопах. Подобная динамика показателя может означать благоприятность условий произрастания растения.

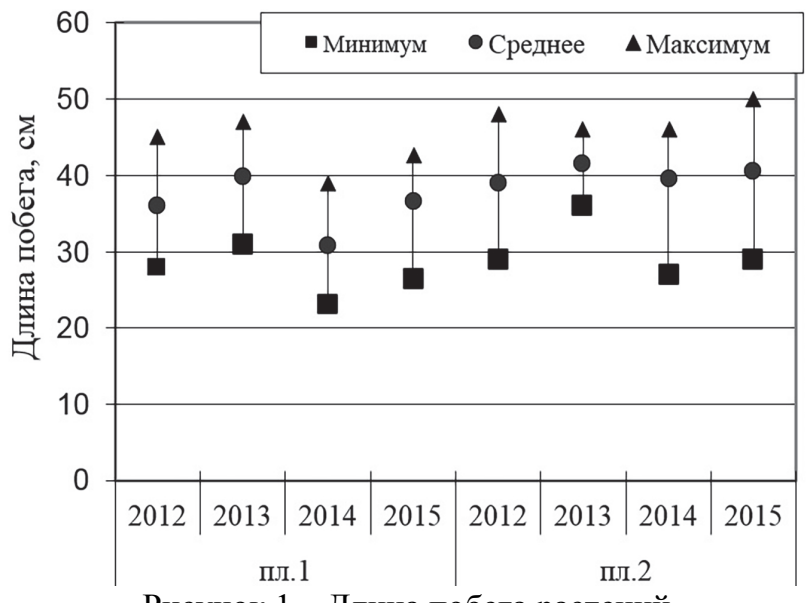

Рисунок 1 - Длина побега растений

тюльпана Биберштейна в квартале 80

Обе площади сбора тюльпана являлись открытыми, поэтому различия в длине побега растений разных ценопопуляций, скорее всего, зависят от благоприятности почвенно-грунтовых условий биотопов (засолённости почв, содержании влаги и др.). Макси- мальная средняя длина побега у растений 2 учетной площади также может быть связана с меньшим числом видов-конкурентов в обследованном биогеоценозе.

Ранжирование рядов данных и построение на их основе графиков распределения представлено на рис. 2 и 3. Так, для растений тюльпана в популяционной группе на первой пробной площади (рис. 2) отмечено одновершинное распределение, говорящее о выраженности группы растений со сходными морфометрическими показателями.

В 2012, 2013 и 2015 гг. отмечается преобладание числа особей с высотой побега около 41 см, в 2014 г. наибольшую долю все растений составили особи с высотой в 34 см. В 2012 и 2013 гг. доля высоких растений составила $50-60 \%$ от общего числа особей, в 2015 г. данное количество достигло 80\%. Для популяционной группы на пробной площади 2 (рис. 3 ) доля растений с высотой побега около 41 см была максимальной во все годы, но в 2012, 2014 и 2015 гг. распределение характеризовалось одновершинностью, а в 2013 г. распределение носило плосковершинный характер, что можно расценить как нестабильность показателя. В 2013 г. появился дополнительный максимум - группа более высоких растений (высота побега ок. 48-50 см). Это может означать, что в 2014 г. повышенный тепловой режим и некоторая ограниченность увлажнения способствовали активному росту цветоносных побегов.

Сравнивая динамику показателя у растений двух популяционных групп тюльпана, мы можем отметить, что на обеих площадях доля высокий растений (от 36 см) составила больше полвины выборки. Распределение длины побега у особей второй популяционной группы более стабильно, изменения в зависимости от года вегетации слабо выражены.

Что касается изменчивости признака длины побега, значения коэффициента вариации подтвердили заметную пластичность данного признака, что вполне согласуется с биоэкологической спецификой побега. Коэффициент вариации (рис. 4) находится в пределах 7-13\%, не превышая отметку 20\%. В 2012 г. значения коэффициента вариации были схожими.

Таким образом, показатель длины побега тюльпана Биберштейна у растений из популяции квартала 80 в 2012-2015 гг. в пределах всей выборки варьирует в промежутке значений от 23 см до 50 см, максимальная средняя длина (40 см) представлена у растений второй популяционной группы. Сравнивая динамику показателя у растений двух популяционных групп тюльпана, мы можем отметить, что на обеих площадях доля высоких растений (от $36 \mathrm{cm)} \mathrm{составила}$ больше половины выборки. Распределение длины побега у особей второй популяционной группы более стабильно, изменения в зависимости от года вегетации слабо выражены. Признак длины побега характеризуется пластичностью, его значения вписываются в диапазон значений, указанный для различных частей ареала в литературе, при значительной доле «высоких» растений в обследованной популяции. Данный факт может свидетельствовать о благоприятности условий произрастания и возможности сохранения в составе растительных сообществ при отсутствии лимитирующих антропогенных факторов. 
Котельникова М.Г.

К оценке биоэкологических особенностей растений тюльпана..

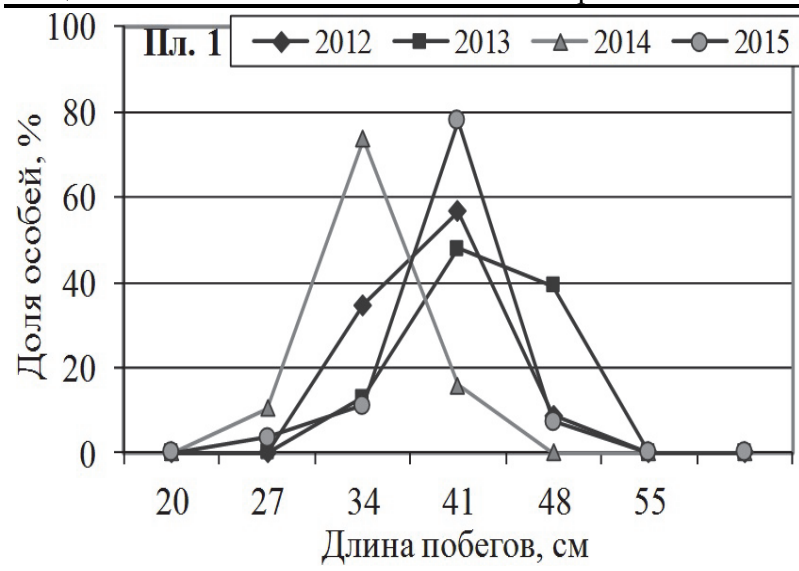

Рисунок 2 - Средняя длина побега растений тюльпана Биберштейна учетной площади №1 квартала 80

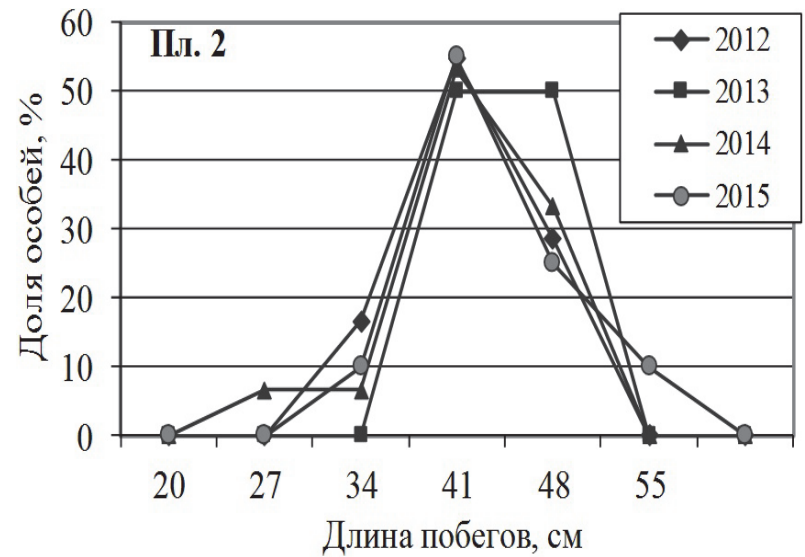

Рисунок 3 - Средняя длина побега растений тюльпана Биберштейна учетной площади №2 квартала 80

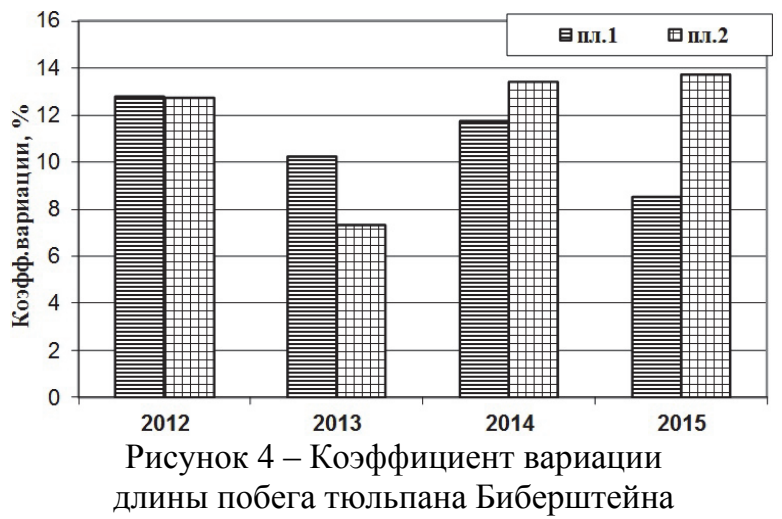

\section{СПИСОК ЛИТЕРАТУРЫ:}

1. Кавеленова Л.М., Прохорова Н.В., Головлёв А.А., Розно С.А. Сохранение фиторазнообразия как составная часть стратегии устойчивого развития Самарской области // Поволжский экологический журнал. 2014. № 1. C. 12-20.

2. Красная книга Самарской области. Т. 1. Редкие виды растений, лишайников и грибов / под ред. чл.корр. РАН Г.С. Розенберга и С.В. Саксонова. Тольятти: ИЭВБ РАН. 2003. 400 с.

3. Grunert C.H. Gartenblumen von A bis Z. Leipzig, 1975. $619 \mathrm{p}$.

4. Кудрявцева В.М. Тюльпаны. Минск: Полымя, 1987. С. 14.

5. Данилевская О.Н. Тюльпаны. Л.: Лениздат, 1969. $95 \mathrm{c}$.

6. Декоративные многолетники. М.: АН СССР, 1960. $333 \mathrm{c}$.
7. Энциклопедия декоративных садовых растений [Электронный ресурс] // http://flower.onego.ru/lukov/ tulipa/19.html.

8. Черепанов С.К. Сосудистые растения России и сопредельных государств (в пределах бывшего СССР). Русское издание. СПб.: Мир и семья, 1995. $992 \mathrm{c}$.

9. Бочанцева 3.П. Тюльпаны: морфология, цитология и биология. Ташкент: АН УзССР, 1962. 408 с.

10. Горелов М.С., Матвеев В.И., Устинова А.А. Природа Куйбышевской области. Куйбышев: Кн. издво, 1990.464 с.

11. Иллюстрированный определитель растений Средней России. Т. 1. Папоротники, хвощи, плауны, голосеменные, покрытосеменные (однодольные) / И.А. Губанов, К.В. Киселёва, В.С. Новиков, В.Н. Тихомиров. М.: Т-во научных изданий КМК, Ин-т технологических исследований. 2003. С. 476.

12. Кудрявцева В.М. Тюльпаны. Минск: Полымя, 1987.14 с.

13. Определитель высших растений Башкирской АССР / Ю.Е. Алексеев, Е.Б. Алексеев, К.К. Габбасов и др. М.: Наука, 1988. С 184.

14. Определитель растений Среднего Поволжья / под ред. В.В. Благовещенского. Л.: Наука, 1984. С. 296.

15. Плаксина Т.И. Конспект флоры Волго-Уральского региона. Самара: Самарский университет. 2001. $388 \mathrm{c}$.

16. Плаксина Т.И. Редкие, исчезающие растения Самарской области: учеб. пособие. Самара: Самарский университет, 1998. 272 с.

17. Красная книга Липецкой области. Растения, грибы, лишайники. Изд. 2-е, перераб. / под ред. А.В. Щербакова 2014. 696 с.

18. Красная Книга Республики Мордовия. Т. 1. Редкие виды растений, лишайников и грибов. Саранск: Мордовское книжное издательство, 2003. 288 с.

19. Красная книга Курганской области. Издание 2е. Курган: Изд-во Курганского гос.ун-та, 2012. 448 с.

20. Травянистые растения СССР / Ю.Е. Алексеев, В.Н. Вехов, Г.П. Гапочка, Ю.К. Дундин. и др. М.: Мысль, 1971. С. 295.

21. Красная книга Республики Башкортостан (объединенный том) / под ред. А.А. Фаухутдинова. - Уфа: Полипак, 2007. 528 с.

22. Маевский П.Ф. Флора средней полосы европейской части России. М.: Товарищество научных изданий КМК, 2006. 600 с.

23. Зернов А.С. Флора Северо-Западного Кавказа. М.: Товарищество научных изданий КМК. 2006. 186 с.

24. Терехов А.Ф. Определитель весенних и осенних растений Среднего Поволжья и Заволжья. Куйбышев: Куйбышевское книжное издательство, 1969. С. 388 .

25. Красная книга Пензенской области. Т. 1. Грибы, лишайники, мхи, сосудистые растения. Издание второе. Пенза, 2013. 300 с.

26. Красная книга Ульяновской области (растения): в 2 т. / Под научной ред. Н.С. Ракова; Правительство Ульяновской области. - Ульяновск: УлГУ, 2005. T. 2. $220 \mathrm{c}$.

27. Красная книга Челябинской области: животные, растения, грибы / Министерство по радиацион- 
ной и экологической безопасности Челябинской области, Ин-т экологии растений и животных УрО РАН; отв. ред. Н.С. Корытин. Екатеринбург: Изд-во Урал. ун-та, 2005. $450 \mathrm{c.}$

28. Зелёная книга Поволжья: Охраняемые природные территории Самарской области. Самара: Кн. издво, 1995. С. 150-200.

29. Саксонов С.В. Самаролукский флористический феномен. М.: Наука, 2006. 120 с.

30. Саксонов С.В. О видах растений, лишайников и грибов Красной книги Российской Федерации // Самарская Лука: Бюллетень. 2006. № 17. С. 253-285.

31. Ужамецкая Е.А. Васильково-качимовая ассоциация // Зелёная книга Самарской области: редкие и охраняемые растительные сообщества. Самара: СамНЦ РАН, 2006. С. 133-134.

32. Флора памятника природы «Гора Зелёная» Елховского района Самарской области / С.В. Саксонов, А.В. Лобанова, А.И. Иванова, В.Н. Ильина и др. //
Вестник Волжского университета им. В.Н. Татищева. Серия «Экология». 2005. Вып. 5. С. 6, 20.

33. Флористическое разнообразие особо ценного Красносамарского лесного массива Самарской области: I. Сосудистые растения // Самарская Лука: проблемы региональной и глобальной экологии. Тольятти: Кассандра, 2010. Т. 19. № 1. С. 112-113, 127.

34. Матвеев Н.М., Филиппова К.Н., Дёмина О.Е. Систематический и экоморфный анализ флоры Красносамарского лесного массива в зоне настоящих степей // Вопросы экологии и охраны природы в лесостепной и степной зонах: Межвед. сб. науч. тр. Самара: Самарский университет. 1995. С. 41-71.

35. Оценка состояния флористического фиторазнообразия особо ценного Красносамарского лесного массива в целях научного обоснования проведения мероприятий по его охране и рациональному использованию (Отчет о НИР). Самара: 2008, 214 с.

\section{THE ASSESSMENT OF BIO-ECOLOGICAL FEATURES OF PLANTS TULIPA BIEBERSTEINIANA SCHULT. ET SCHULT. FIL. IN THE MODEL FOREST HABITATS OF THE KRASNOSAMARSKY FOREST}

(C) 2016

\section{M.G. Kotelnikova, postgraduate student of the Chair of Ecology, Botany and Nature Protection} Samara National Research University, Samara (Russia)

Abstract. The paper presents some preliminary results of the monitoring of Tulipa biebersteiniana Schult. et Schult. fil. plants (category of rare and endangered plant species). By summarizing the available sources of science literature we have compiled a general description of morphological and bio-ecological species characteristics. The results of the field study fulfilled in 2012-2015 in two population groups of the Krasnosamarsky forestry (Samara region) were used to determine morphometric parameters of Tulipa biebersteiniana plants. The data also helped us to assess the variability level and to make a comparison with plant quantitative traits given in the literature. It was found that the shoot length of Tulipa biebersteiniana plants varied in the range of $23 \ldots 50 \mathrm{~cm}$, the maximum average length of $40 \mathrm{~cm}$ are presented in plants of population group number two. The distribution of shoot length among individuals of the second population group is more stable, changes depending on the year of vegetation are poorly expressed. The lengths of shoots inside the range specified for the various parts of the area in the literature with a significant proportion of «high» plants in the population is studied. This may be a sign of good growth conditions for Fritillaria rutheni$c a$ that gives an opportunity to the plant conservation in natural communities in the absence of limiting anthropogenic factors.

Keywords: Tulipa biebersteiniana Schult. et Schult. fil.; morphological and bioecological features; quantitative and qualitative characteristics; shoot length; Krasnosamarsky forest; model biotope; Samara Region.

УДК 631.417 .2

\section{АГРОГЕННАЯ ТРАНСФОРМАЦИЯ ОРГАНИЧЕСКОГО ВЕЩЕСТВА ЧЕРНОЗЁМОВ КАЗАХСТАНА}

(C) 2016

А.К. Куришбаев, доктор сельскохозяйственных наук, профессор, председатель правления

Г.А. Звягин, докторант кафедры почвоведения и агрохимии

Казахский агротехнический университет им. С. Сейфуллина, Астана (Казахстан)

Н.В. Ярославцева, кандидат сельскохозяйственных наук,

научный сотрудник отдела биологии и биохимии почв

Б.М. Когут, доктор сельскохозяйственных наук, заведующий отделом биологии и биохимии почв

Почвенный институт им. В.В. Докучаева, Москва (Россия)

Аннотация. В настоящее время, несмотря на широкую изученность временной динамики органического вещества пахотных почв в глобальном масштабе, значительный научный интерес представляет установление закономерностей его количественной трансформации на региональном уровне в зависимости от систем сельскохозяйственного использования с целью уточнения общемировых оценок запасов гумуса в связи с проблемой «парникового эффекта». В связи с этим была исследована современная динамика (1990-2015 гг.) органического вещества черноземов обыкновенных и южных в условиях длительных стационарных полевых опытов основного зерносеющего региона Северного Казахстана. На основании разновременных данных по содержа- 